for computing logarithms as well as antilogarithms; and thus, not only made the operations more convenient, but also caused one set of preparatory tables to he sufficient.

The principal table in Gray's book above-named consists of the logarithms to twenty-four places of all the possible factors $\mathbf{x}+(\cdot 0 \mathrm{x})^{n} \times r$, up to that limit. An auxiliary table contains, also to twenty-four places, the logarithms and their complements of the natural numbers I to 9 , these being frequently required to "prepare" the given number. A smaller table to twelve figures only appeared, as already mentioned, in the Journal of the Institute of Actuaries, and was subsequently published separately by Messrs. C, and E. Layton ; but as the twenty-four-figure table can be worked quite easily to any extent up to that limit, there is no particular advantage in the smaller one.

By means of Gray's tables the work of forming logarithms and antilogarithms is reduced to a minimum, and the process is so simple that any arithmetician can perform it, the more especially as many numerical examples are given in the introduction.

London, January 23. GEORGE KING.

\section{Note on a Problem in Maxima and Minima.}

To find a point such that the sum of the straight lines joining it with the angular points of a given triangle shall be a minimum.

This problem was proposed by Fermat to Torricelli, who solved it, and sent it to Vincent Viviani, who also solved it, but called it a problem "quiod, ut vera fateor, non nisi iteratis oppugnationibus tunc nobis vincere datum fuit."

The solution is given in Gregory's "Examples of the Differential and Integral Calculus," and in Todhunter's "Differential Calculus," pp. 240-42.

Yet it can be solved in the most elementary manner.

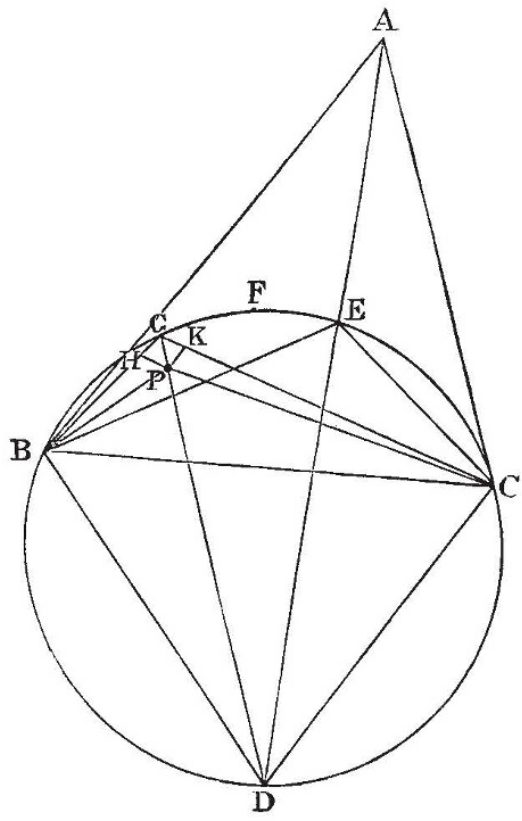

Let $\mathrm{ABC}$ be the triangle. Describe an equilateral triangie on $\mathrm{BC}$ on the side remote from $\mathrm{A}$. Describe a circle round the triangle $\mathrm{BCD}$. Join $\mathrm{AD}$. Then $\mathrm{E}$ is the point required. Join $\mathrm{BE}, \mathrm{CE}$.

(I) It follows, from Euc. vi. D, that $\mathrm{BE}+\mathrm{EC}=\mathrm{ED}$, $\therefore \mathrm{BE}+\mathrm{EC}+\mathrm{AE}=\mathrm{AD}$,

and evidently $\angle \mathrm{BEC}=\mathrm{BEA}=\mathrm{AEC}=\mathrm{1} 20^{\circ}$.

(2) Let $\mathrm{F}$ be a point on the circumference $\mathrm{BC}$.

$$
\mathrm{BF}+\mathrm{FC}=\mathrm{FD} \quad \text { (Euc. vi. } \mathrm{D} \text { ), }
$$$$
\therefore \mathrm{BF}+\mathrm{FC}+\mathrm{FA}=\mathrm{FD}+\mathrm{FA}>\mathrm{AD} \text {. }
$$

(3) Let $P$ be a point not on the circumference. Join DP, and produce it to the circumference at $\mathrm{G}$. Let fall the perpendiculars $\mathrm{PH}$ and $\mathrm{PK}$, on $\mathrm{GB}$ and $\mathrm{GC}$ respectively.

$$
\begin{gathered}
\text { By Euc. i. } 26, \mathrm{GH}=\mathrm{GK}=\frac{1}{2} \mathrm{GP} . \\
\text { Since } \angle \mathrm{GPH}=30^{\circ}=\mathrm{GPK}, \\
\therefore \mathrm{BH}+\mathrm{KC}=\mathrm{PD}, \\
\therefore \mathrm{BP}+\mathrm{PC}>\mathrm{PD}, \\
\text { B } \mathrm{BP}+\mathrm{PC}+\mathrm{PA}>\mathrm{PD}+\mathrm{PA}>\mathrm{AD} .
\end{gathered}
$$

(4) It also follows from the above that if $\angle \mathrm{A}=\mathrm{J} 20^{\circ}$, then the point required is $\mathrm{A} \equiv \mathrm{E}$.

If $\angle \mathrm{A}>120^{\circ}$, the point $\mathrm{A}$ will be within the circle, and $\mathrm{A}$ itself will be the point required.

R. CHAR'TREs.

\section{Note on the Dimensions and Meaning of $J$, usually} called the Mechanical Equivalent of Heat.

THE title "mechanical equivalent of heat" tends to make one consider that I means the ratio of a quantity of mechanical energy to an equivalent quantity of heat; but since heat is mechanical energy (in a molecular form) it follows that $\mathrm{J}$ on this supposition is equal to unity, and therefore unnecessary.

Another way in which $\mathrm{J}$ is sometimes regarded is as the ratio between the ordinary units of heat and work; that is to say, in England, it is the ratio of the British thermal unit to a footpound, viz. the number 772 . This definition makes it a simple number, the number of work units in a heat unit, a number which depends on the units of heat and work employed, and is different in France and England.

Now although $J$ generally has one or other of these significations-that is, must be either unity or some pure number-yet people speak of the dimensions of $\mathrm{J}$ as being, not zero, but Work

\section{Mass $\times$ Temperature}

It is evident that there must be some confusion here, a confusion arising from the fact that most people when talking of quantities mean only so many times the units of those quantities, and so are not always sufficiently careful about the definitions of the various quantities which they introduce.

Now if we confine our attention to quantities themselves, independently of any systems of measurement, we shall be led to a perfectly consistent mode of regarding J, a way moreover in which it will have the required dimensions Work

Mass $\times$ Temperature

A British thermal unit is the heat required to raise a pound of water at freezing-point through $\mathrm{I}^{\circ} \mathrm{F}$., and Joule discovered that the mechanical equivalent of that amount of heat was about 772 foot-pounds.

Hence if we wish to consider the work necessary to raise any other mass of water at freezing-point through any small range of temperature, we have only to notice that the quantity $\frac{\text { Work }}{\text { Mass } \times \text { Range of Temperature }}$ is constant, and equal

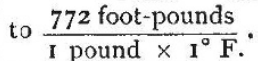

This quantity is very fitly denoted by $\mathrm{J}$, and might, if thought convenient, be called a Joule.

But this quantity is the specific heat of water, according to the definition that specific heat is the heat required to raise a mass through a small range of temperature divided by the mass and the range. So that we have arrived at these conclusions : a quantity of heat is the same thing, whether expressed in British thermal units, or in foot-pounds, or in terms of any other standard; and the specific heat of water at $0^{\circ} \mathrm{C}$. is denoted by the letter $\mathrm{J}$.

Indeed it may be said that the result of Joule's experiments is the determination of the specific heat of water in absolute measure. Again, if $c$ is the ratio of the specific heat of any substance to that of water, the full expression of its specific heat is $\mathrm{cJ}$; that is, its specific heat is some multiple or fraction of a Joulc.

The first law of thermo-dynamics will then be expressed as-

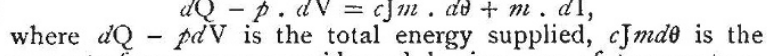
amount of new energy evidenced by increase of temperature, and $m d \mathrm{I}$ is the increment of the latent energy of the body.

Coopers Hill, Staines, January 19. ALFRED LODGE. 